\title{
O FEDERALISMO SANITÁRIO BRASILEIRO E A REGIONALIZAÇÃO DA SAÚDE NO ESTADO DE PERNAMBUCO
}

\author{
THE BRAZILIAN SANITARY FEDERALISM AND THE HEALTH REGIONALITAZION AT \\ PERNAMBUCO STATE
}

\author{
José Roberto Henrique Souza Soares \\ Universidade Federal de Pernambuco (UFPE) \\ roberto.henriquesoares@ufpe.br \\ Anselmo César Vasconcelos Bezerra \\ Instituto Federal de Educação, Ciência e Tecnologia de Pernambuco (IFPE) \\ anselmo@recife.ifpe.edu.br \\ Alcindo José de Sá \\ Universidade Federal de Pernambuco (UFPE) \\ alcindo-sa@uol.com.br
}

\begin{abstract}
RESUMO
A Constituição Federal de 1988 inaugurou uma estratégia política inédita no país, ao conceber os municípios como entes federados com o mesmo nível de articulação que os Estados e a União garantiu assim a descentralização das ações e serviços públicos. $\mathrm{Na}$ Saúde essa tendência foi reafirmada constituindo o que Dourado e Elias (2011) enunciam como federalismo sanitário brasileiro. Assim, busca-se por meio deste levantamento bibliográfico e documental, compreender como a instituição do federalismo sanitário brasileiro auxiliou na constituição das Regiões de Saúde e como ao longo das décadas recentes essa estratégia política foi sendo adotada no estado de Pernambuco. O processo de constituição das regiões na saúde busca garantir o acesso universal e igualitário da população de maneira descentralizada e eficiente. Nesse sentido, ao longo dos anos foram estabelecidas diretrizes que constituíram a regionalização da saúde no Brasil por meio da descentralização. No entanto, essas regiões ainda apresentam inúmeros entraves que dificultam o sucesso da política de regionalização em saúde no Brasil.
\end{abstract}

Palavras-Chaves: Descentralização. Regionalização. Sistema Único de Saúde (SUS).

\begin{abstract}
The Federal Constitution of 1988 inaugurated an unprecedented political strategy in the country, conceiving the towns as federated entities with the same level of articulation as the States and the Union thus guaranteed the decentralization of public actions and services. In Health this trend was reaffirmed constituting what Dourado and Elias (2011) enunciate as brazilian sanitary federalism. From this perspective, this bibliographical and documentary survey seeks to understand how the institution of Brazilian federalism helped in the formation of health regions and how, over recent decades, this political strategy was adopted in the state of Pernambuco. The constitution of health regions seeks to ensure universal and equal access to the population in a decentralized and efficient manner. In this sense, over the years, guidelines have been established that constituted the regionalization of health in Brazil through decentralization. However, in these regions still present numerous obstacles that hinder the success of the regionalization policy in health from Brazil.
\end{abstract}

Keywords: Decentralization. Regionalization. Unified Health System.

Recebido em: 08/03/2019

Aceito para publicação em: 21/02/2020 


\section{INTRODUÇÃO}

As regiões de saúde se constituem como estratégias de organização político territorial do Sistema Único de Saúde (SUS). Na perspectiva de Lima et al (2012), a regionalização na saúde é um processo político, estabelecido pelas relações entre os diferentes atores sociais no espaço geográfico, almejando o desenvolvimento de estratégias e instrumentos para o planejamento, a integração, a gestão, a regulação e o financiamento de uma rede de ações e serviços de saúde. Tal processo é fundamentado em uma das diretrizes presentes no texto da Constituição Federal de 1988 que trata dos serviços de saúde no Brasil, destacando que estes devem se desenvolver objetivando a equidade, universalidade, descentralização e regionalização.

A estratégia de organização espacial da saúde no Brasil é um exemplo claro de como os conceitos e categorias geográficas apresentam funcionalidade para a vida em sociedade. A contribuição que a Geografia, enquanto conhecimento capaz de refletir sobre a realidade dos homens em sua relação com o espaço, pode desenvolver para auxiliar na organização e definição das regiões de saúde, conforme elucida Guimarães (2008), tem sido centrada na compreensão da produção do espaço. A organização espacial da política de saúde adotada no Brasil foi influenciada pelos mecanismos de descentralização e valorização municipal adotadas nos anos inaugurais do SUS.

No entanto, conforme discutem Barcellos e Bastos (1996), a contribuição da Geografia não se limita à análise espacial. Por meio da compreensão interdisciplinar de uma série de produtos cartográficos, é possível obter uma visão global da realidade, num esforço de síntese geográfica. Nesse sentido, é possível compreender como as delimitações territoriais utilizadas na política pública de saúde tem proporcionado o acesso da população aos serviços disponíveis.

Enquanto política pública, a saúde no Brasil estabelece a territorialização como um dos princípios básicos para a descentralização do serviço prestado, por meio de uma organização em Regiões e Redes. Essa organização socioespacial, de acordo Brevilheri, Narciso e Pastor (2014), visa considerar a heterogeneidade das cidades brasileiras, contribuindo com o avanço das estratégias de ação da política de saúde para além do atendimento das demandas setorizadas. "As ações no território devem considerá-lo como espaço concreto, em permanente construção, como um campo geossocial dinâmico, onde se criam formas de atendimento dos indivíduos e grupos sociais." (BREVILHERI; NARCISO; PASTOR. 2014, p. 58). A política de saúde nesse sentido necessita se adequar as diferentes realidades socioespaciais que compõe o país.

Nessa perspectiva, busca-se por meio deste levamento bibliográfico e documental, com características metodológicas qualitativas, compreender como o processo cooperativo estabelecido pelo federalismo institucional promulgado na Constituinte de 1988 contribuiu para a organização do SUS, através das estratégias de descentralização e regionalização. Descreve-se ainda, como os elementos norteadores do sistema de saúde do Brasil ao longo dos anos contribuíram para a organização espacial dos serviços de saúde em Pernambuco, relatando o processo histórico de afirmação da regionalização da saúde no estado abordado, por meio da análise dos documentos que nortearam as ações da Secretaria Estadual de Saúde (SES) do estado de Pernambuco, desde o ano de 2002.

Este trabalho estrutura-se por meio de duas sessões que estão interconectadas. Na primeira parte destaca-se os fundamentos teóricos, políticos e documentais que contribuíram para a conformação do federalismo sanitário brasileiro, indicando como os primeiros passos desse processo coincidiram com a necessidade de regionalização da saúde no Brasil. Na parte seguinte, busca-se elucidar de maneira prática e teórica como a regionalização da saúde no estado de Pernambuco estruturou-se ao longo dos anos e foi adaptando-se as propostas e leis promulgadas pelo estado e pela federação. Busca-se assim, compreender como o SUS foi estruturado ao longo dos anos recentes e como estas transformações foram absorvidas e praticadas em Pernambuco.

\section{FEDERALISMO SANITÁRIO BRASILEIRO NA CONFORMAÇÃO DAS REGIÕES DE SAÚDE}

Com a Constituição de 1988 o Brasil passou a experimentar um período de descentralização, impulsionada pela Carta Constituinte, que garantiu autonomia aos municípios no mesmo nível dos estados e da União. Esse preceito também foi responsável, de acordo com Dourado e Elias (2011), por fundamentar o que os autores enunciaram como federalismo sanitário brasileiro. Nesse sentindo, 
a organização institucional do SUS estrutura-se obedecendo a tríplice aliança governamental, pela qual cada ente federado (União, Estados e Municípios) apresenta autonomia na gestão de ações e serviços de saúde em seus territórios.

No decurso do federalismo brasileiro, anteriormente a promulgação da Constituição de 1988, o país vivenciou ciclos descentralizadores e centralizadores bem definidos. Dourado e Elias (2011), definem o modelo federativo adotado na Carta Constituinte em vigor como um modelo cooperativo, uma vez que delimitou a trina federativa as competências e responsabilidades em mesmo nível. Nessa perspectiva valorizou-se as características locais na tomada de decisões, além de impulsionar a transferência de encargos e recursos para os governos municipais, responsabilizando-os pelo provimento de bens e serviços aos cidadãos.

Nesse contexto, o SUS foi elaborado e pensado conforme as orientações dispostas na Carta Constituinte de 1988. Tal documento em seu artigo 198 define, de acordo com Brasil (2016), que as ações e serviços de saúde devem ser organizados por meio de uma rede regionalizada e hierarquizada, constituindo um sistema único, organizada através de diretrizes, das quais se destacam a descentralização, a integralidade e a participação comunitária. Dessa forma, a organização política dos serviços de saúde no Brasil desde sua oficialização na Constituição Federal, se organizam espacialmente por meio de redes e regiões.

Durante o percurso dos anos, vários instrumentos legislativos contribuíram para que o sistema de saúde adotado atualmente no Brasil fosse constituído. Viana et al (2018) observam que desde a década de 1980 até os dias atuais, são identificados dois traços distintos, em períodos bem delimitados, que confluíram para a organização político espacial do SUS, conforme representado no quadro 1. Os dois momentos se distinguem entre si, de acordo com Reis et al (2017), devido a tendências inicialmente voltadas a descentralização e posteriormente objetivando a regionalização, presentes nas leis e diretrizes que regulamentaram o SUS ao longo de sua formação.

Entre as décadas de 1980 e 2000 as estratégias de regulamentação da saúde no Brasil indicavam o caminho da descentralização. Conforme esclarecem Reis et al (2017), essa estratégia buscava a ampliação dos cuidados, a integração dos serviços de saúde, a multiplicação das áreas de decisão, de ação e a diminuição do controle da esfera central sobre as demais. No entanto, de acordo com Dourado e Elias (2011), as Normas Operacionais Básicas (NOBs) que delimitaram as ações de saúde durante a década de 1990, valorizaram unicamente a municipalização dos serviços negligenciando a importância da organização regional. Tal condição foi superada, a partir da década de 2000 , quando a regionalização do SUS passou a ser concebida como fator preponderante e indispensável para que as ações descentralizadoras surtissem efeitos.

Os preceitos constitucionais que regem a política de saúde pública, conforme Guimarães (2005), visam garantir a integração das atividades e ações em um sistema único, capaz de integrar em sua organização econômica, política e espacial as três esferas do poder federativo, cada uma exercendo sua autonomia e participação. Essa mudança constitucional é considerada um avanço importante no caminho para a universalização da saúde no Brasil.

Nessa perspectiva, as regiões impõem aos entes federados uma relação de solidariedade e partilha impulsionando a conformação de verdadeiros territórios sanitários. $\mathrm{Na}$ concepção de Mendes (2011), tais territórios diferenciam-se dos territórios políticos-administrativos, que ainda permanecem vigentes em muitas regiões do Brasil, por meio da abrangência das ações e serviços, bem como pela responsabilidade dos gestores que atuam no setor da saúde de cada ente federado.

A integralidade na atenção à saúde sob a perspectiva dos municípios, conforme definiu Fernandes (2017), ainda se constitui como uma condição inatingível se percebida de maneira isolada, fora da rede de atenção à saúde. Portanto, o discurso da racionalidade e a "necessidade de compartilhamento, otimização e maximização de recursos de ordem física, financeira e humana para que os problemas de saúde sejam sanados e prevenidos" (FERNANDES, 2017. p.1312) se configuram como estratégias indispensáveis para que exista uma rede integrada. Tal conexão necessita existir entre todos entes federados, para que possibilitem o acesso aos serviços de saúde pública de forma universal e igualitária. 
Quadro 1 - Estratégias Políticas Adotadas no Âmbito do SUS a partir da Constituição de 1988

\begin{tabular}{|c|c|c|c|}
\hline & Estratégia Política & $\begin{array}{c}\text { Período/Ano } \\
\text { de } \\
\text { Promulgação }\end{array}$ & Descrição \\
\hline \multirow{5}{*}{$\begin{array}{l}\mathrm{D} \\
\mathrm{E} \\
\mathrm{S} \\
\mathrm{C} \\
\mathrm{E} \\
\mathrm{N} \\
\mathrm{T} \\
\mathrm{R} \\
\mathrm{A} \\
\mathrm{L} \\
\mathrm{I} \\
\mathrm{Z} \\
\mathrm{A} \\
\mathrm{C} \\
\mathrm{A} \\
\mathrm{O}\end{array}$} & $\begin{array}{l}\text { Instituto Nacional de } \\
\text { Assistência Médica da } \\
\text { Previdência (INAMPS) }\end{array}$ & $\begin{array}{l}\text { Meados de } \\
1980 \text { a } 1990\end{array}$ & $\begin{array}{l}\text { Estratégia em que os estados e municípios recebiam recursos } \\
\text { financeiros pela prestação de serviços de assistência à saúde } \\
\text { por meio de convênios. }\end{array}$ \\
\hline & $\begin{array}{l}\text { Sistema Unificado e } \\
\text { Descentralizado de } \\
\text { Saúde (SUDS) }\end{array}$ & 1987 a 1988 & $\begin{array}{l}\text { Resultou do avanço do INAMPS e contribuiu diretamente para a } \\
\text { constituição SUS. Transferiu para os estados serviços e } \\
\text { servidores federais, além da execução de convênios com os } \\
\text { municípios financiados pela União. }\end{array}$ \\
\hline & $\begin{array}{l}\text { Normas Operacionais } \\
\text { Básicas (NOB 01/91) }\end{array}$ & 1991 & $\begin{array}{l}\text { Definiu que municípios e estados deviam atuar como meros } \\
\text { prestadores de serviços da União. Os recursos ainda eram } \\
\text { repassados de acordo com a tabela do INAMPS. E não propôs } \\
\text { nenhum arranjo regional para o sistema. }\end{array}$ \\
\hline & $\begin{array}{l}\text { Normas Operacionais } \\
\text { Básicas (NOB 01/93) }\end{array}$ & 1993 & $\begin{array}{l}\text { Essa norma objetivou disciplinar a descentralização da Gestão } \\
\text { do sistema de saúde nacional. Institucionalizou as comissões } \\
\text { Intergestores (CIT) e Bipartite (CIB), dando centralidade na } \\
\text { escala federal aos Conselhos Nacionais de Secretários de } \\
\text { Saúde (CONASS) e ao de Secretarias Municipais de Saúde } \\
\text { (CONASEMS). Nesse novo modelo a regionalização passou a } \\
\text { ser entendida como um processo de articulação e mobilização } \\
\text { municipal em torno dos aspectos econômicos locais. }\end{array}$ \\
\hline & $\begin{array}{l}\text { Normas Operacionais } \\
\text { Básicas (NOB 01/96) }\end{array}$ & 1996 & $\begin{array}{l}\text { Apresentou forte componente municipalista, consolidando o } \\
\text { pleno exercício e a centralidade dos municípios na Gestão do } \\
\text { Sistema de Saúde. Nesta norma os poderes estadual e federal } \\
\text { assumiam a responsabilidade de corresponsáveis, atuando } \\
\text { apenas na ausência das funções cabíveis a esfera municipal. }\end{array}$ \\
\hline \multirow{5}{*}{$\begin{array}{l}\mathbf{R} \\
\mathrm{E} \\
\mathbf{G} \\
\mathbf{I} \\
\mathbf{O} \\
\mathrm{N} \\
\mathrm{A} \\
\mathrm{L} \\
\mathrm{I} \\
\mathrm{Z} \\
\mathrm{A} \\
\mathrm{C} \\
\mathrm{A} \\
\mathrm{O}\end{array}$} & $\begin{array}{l}\text { Normas Operacionais } \\
\text { de Assistência à } \\
\text { Saúde (NOAS/SUS } \\
\text { 2001) }\end{array}$ & 2001 & $\begin{array}{l}\text { Apresentou como título do documento "A Regionalização da } \\
\text { Assistência à Saúde: aprofundando a descentralização em } \\
\text { equidade no acesso". Essa nova norma deu ênfase ao } \\
\text { planejamento regional integrado, instituiu o Plano Diretor de } \\
\text { Regionalização (PDR) como responsabilidade dos estados e } \\
\text { uma estratégia de planejamento. Além de delimitar os conceitos } \\
\text { chaves que fundamentaram o processo de regionalização. }\end{array}$ \\
\hline & $\begin{array}{l}\text { Normas Operacionais } \\
\text { de Assistência à } \\
\text { Saúde (NOAS/SUS } \\
\text { 2002) }\end{array}$ & 2002 & $\begin{array}{l}\text { Esse novo documento foi lançado com o objetivo de } \\
\text { complementar a NOAS/SUS 2001. Orientando a reorganização } \\
\text { do SUS por meio da regionalização, fortaleceu o papel } \\
\text { coordenador e negociador dos Estados e garantiu a } \\
\text { integralidade da assistência em saúde. }\end{array}$ \\
\hline & $\begin{array}{l}\text { Pacto pela Saúde } \\
\text { (Pacto de Gestão) }\end{array}$ & 2006 & $\begin{array}{l}\text { Essa Portaria do Ministério da Saúde (MS) ressaltou a } \\
\text { regionalização como estratégia essencial para a consolidação } \\
\text { do SUS, através do aprofundamento da descentralização que } \\
\text { deve ocorrer por meio de novos formatos espaciais e outros } \\
\text { instrumentos de planejamento. Definindo ainda esta estratégia } \\
\text { como responsabilidade compartilhada entre as três esferas do } \\
\text { governo. }\end{array}$ \\
\hline & $\begin{array}{l}\text { Redes de Atenção à } \\
\text { Saúde (RAS) }\end{array}$ & 2010 & $\begin{array}{l}\text { O estabelecimento das RAS procurou recuperar o fundamento } \\
\text { constitucional de organização do SUS, estabelecendo o } \\
\text { redesenho e o fortalecimento da Governança a partir da } \\
\text { articulação intermunicipal, interestadual e entre todos os entes } \\
\text { federados. }\end{array}$ \\
\hline & $\begin{array}{l}\text { Decreto Federal } 7.508 \\
\text { de } 2011 \text { que instituiu } \\
\text { o Contrato } \\
\text { Organizativo da Ação } \\
\text { Pública (COAP) }\end{array}$ & 2011 & $\begin{array}{l}\text { Esse decreto conferiu empoderamento legal ao processo de } \\
\text { articulação interfederativa e instituiu legalmente as Regiôes de } \\
\text { Saúde. O COAP, por sua vez, explicitou os consensos e } \\
\text { compromissos pactuados pelos gestores em cada Região e } \\
\text { estabeleceu a alocação de recursos permitida pelas três esferas } \\
\text { de governo, estabelecendo as formas de controle e fiscalização. }\end{array}$ \\
\hline
\end{tabular}

Fonte: REIS et al (2017). Adaptado pelo autor. 
Se faz necessário superar os desafios que o processo de regionalização da saúde ainda enfrenta, Guimarães (2012) destaca como empecilhos a esse processo a adaptação do sistema à heterogeneidade da realidade brasileira, em um país de dimensão continental, o fortalecimento do poder, a liderança local e principalmente o fortalecimento dos municípios. Não na perspectiva de transformá-los em autarquias municipais, conforme definição de Pestana e Mendes (2004), mas que se constituam como porta de entrada do sistema, capaz de atender as demandas da Atenção Básica de Saúde (ABS) de maneira eficiente.

Guimarães (2005) afirma que o maior desafio na busca de regiões de saúde igualitárias são as disparidades e a falta de comunicação entre os integrantes dessa rede nacional. Tal realidade impõe que os atores se articulem formando redes isoladas entre si, constituindo "uma trama multifacetada, com diversos níveis de matizes e modalidades de circulação, distribuição e consumo, inexplicáveis num único nível escalar" (GUIMARÃES, 2005 p. 1024). Assim é necessária uma estratégia que considere de maneira integral as necessidades básicas de cada realidade territorial do país. A equidade dos serviços de saúde prestados à população deve ser uma condição essencial no SUS.

Entre os desafios mais urgentes do SUS estão a ampliação do acesso e a adequação dos serviços ofertados. Conforme destaca, Brasil (2011) a organização de regiões e redes de atenção à saúde tem sido a estratégia de regionalização privilegiada nos últimos anos para superar esses desafios. No entanto, nem sempre as dificuldades que as comunidades mais necessitadas enfrentam com relação a saúde são passiveis de similar solução, uma vez que o país apresenta heterogeneidade marcante.

Diante da disparidade econômica e social que contribui para a diversidade de realidades socioespaciais, Kadri (2019) destaca as dificuldades enfrentadas na Macrorregião Norte brasileira com relação a organização estratégica dos serviços no SUS, confrontando a regionalização como o único caminho possível, diante de um contexto territorial diferente do restante do Brasil. Nesta fração espacial do país predominam populações em sua maioria ribeirinhas e habitantes das florestas e campos, assim a autora indica a Territorialização como uma possível solução, devido a intensa disparidade dos modos de vida, considerando as especificidades necessárias para o cuidado, prevenção e manutenção das condições de saúde da população desta Macrorregião.

As regiões necessitam ser concebidas de maneira integradora sendo capazes de atender as necessidades básicas de atenção à saúde da população. Para Santos e Campos (2015), a regionalização dos serviços de saúde não consegue alcançar seu objetivo por se manter fixa em estruturas que não condizem com as realidades diversas em que estão inseridas. A descentralização dos serviços, a independência operativa e financeira e a centralização federal constituem-se como entraves de difícil gestão, tornando esta abordagem insuficiente administrativamente, necessitando serem superadas para que ocorra um efetivo processo de regionalização da saúde no Brasil.

\section{A REGIONALIZAÇÃO DA SAÚDE NO ESTADO DE PERNAMBUCO}

Os preceitos constitucionais explícitos no art. 198 da Constituição Federal, promulgada no ano de 1988, levaram alguns anos até serem efetivados nos estados e municípios. Em Pernambuco, as estratégias de descentralização e consequentemente regionalização da saúde, só aparecem de maneira explícita em documentos de domínio públicos, divulgados no site da SES de Pernambuco, com o Plano Estadual de Saúde (PES) divulgado no ano de 2006, que organizou as ações de saúde do estado entre os anos de 2005 a 2007. Guimarães (2012) destaca que o estado de Pernambuco buscou implantar a regionalização, através do Pacto pela Saúde, sem um PDR efetivamente consolidado e atualizado, utilizando o PES 2006 para organizar as ideias iniciais de regionalização, tal fato corroborou para a tardia implantação da descentralização e regionalização da saúde no estado, dificultando a organização estratégica de cada ente federado.

Nesse documento, conforme discutido em Pernambuco (2006), observa-se que o aspecto da regionalização aparece de maneira explícita no objetivo geral, considerando-a como um dos princípios as serem alcançados para o aprimoramento do SUS no estado de Pernambuco, porém apenas elencar objetivos não significa a verdadeira implantação do modelo definido teoricamente, é essencial a discussão e efetivação das responsabilidades de cada ente federado e dos gestores envolvidos nesta organização espacial. Este documento constitui-se como resultado de discussões anteriormente realizas, durante os anos de 2001 e 2002 por meio de oficinas em todas as regionais 
de saúde do estado almejando a elaboração de propostas para a organização regionalizada da assistência em saúde, consolidada no Plano Diretor de Regionalização (PDR) vigente da época.

O PDR de que trata Pernambuco (2006), foi promulgado por meio da Resolução da Comissão Intergestores Bipartite (CIB) $n^{\circ}$. 720, em 12 de agosto de 2002, buscando atender as demandas da Norma Operacional de Assistência à Saúde (NOAS - SUS) 01/2002, no entanto este documento não foi consolidado, tornando as definições elaboradas nos anos iniciais obsoletas. Assim, no PES de 2016 a SES de Pernambuco estava estruturada espacialmente por meio de 56 módulos assistenciais de referência para a média complexidade, 10 microrregiões de Saúde, que possuíam polos nas sedes das Regionais de Saúde, que na época também se dividiam em 10 Gerências Regionais de Saúde (GERES) (figura 1). E se estruturavam por meio de 3 macrorregiões com sedes nos municípios de Recife, Caruaru e Petrolina, garantindo os serviços de alta complexidade.

Figura 1 - Gerências Regionais de Saúde (GERES) de Pernambuco em 2002

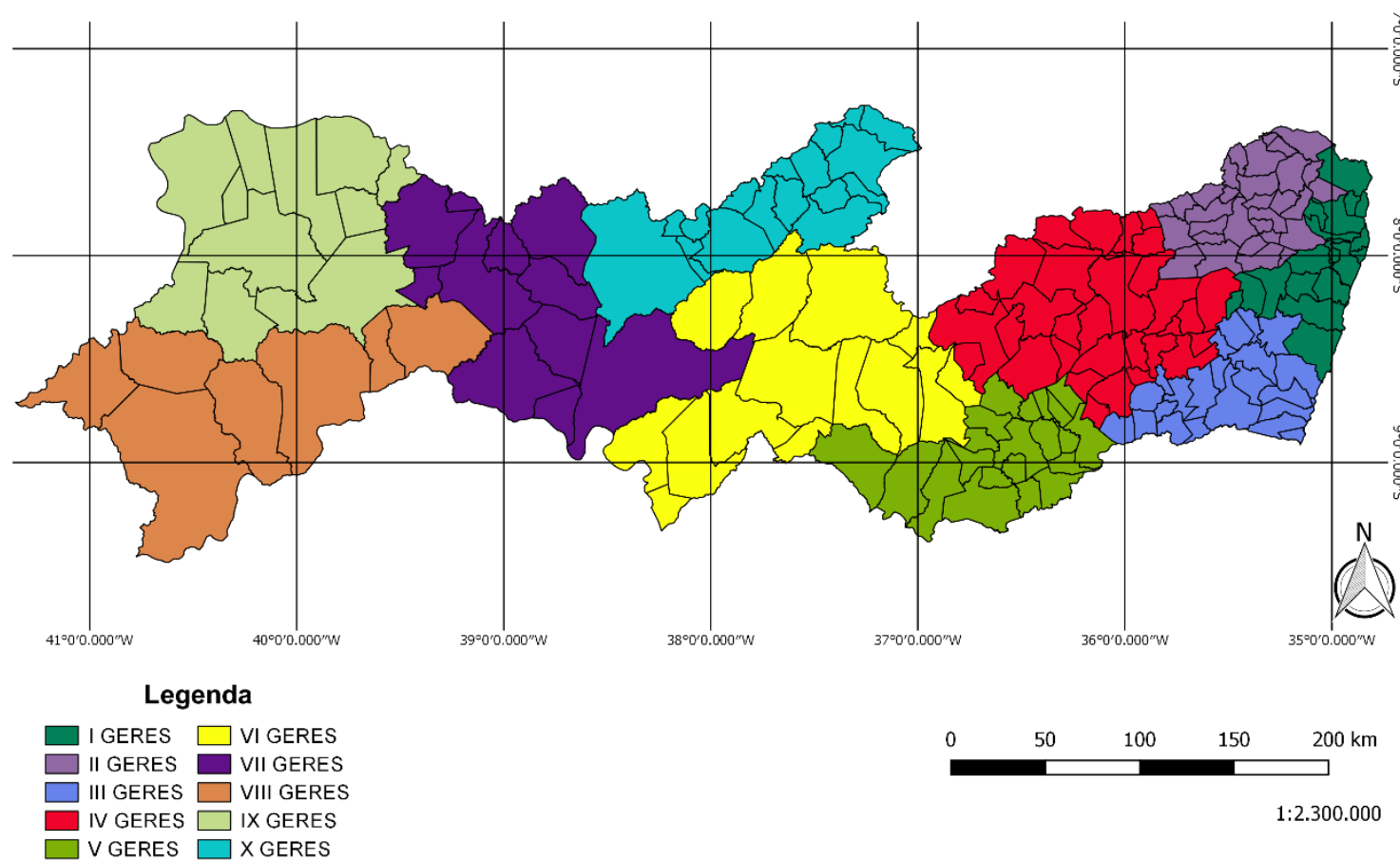

Fonte: PERNAMBUCO, 2006. Adaptado pelo autor.

Sob a organização regional estruturada na figura 1, Pernambuco (2006) destaca que um dos eixos prioritários para que se alcance a descentralização dos serviços e sistemas de saúde é o fortalecimento das dez GERES, adequando-as a estrutura organizacional proposta pelo Pacto de Gestão promulgado no mesmo ano e em conformidade com a NOAS-SUS 01/2002. Determina ainda que o fortalecimento dessas gerências busca ordenar a assistência em territórios delimitados, bem como organizar a estratégia de consórcios intermunicipais de saúde, que fundamentam a organização territorial das GERES. Faz-se também importante a distribuição igualitária dos serviços de média e alta complexidade em todas as regionais, fato que Dubeux e Carvalho (2009) não identificaram utilizando como referência os hospitais regionais, de outra maneira a realidade no estado foi a de concentração de serviços de média e alta complexidade em apenas três GERES.

Para Guimarães (2012), durante esta fase de mudança organizativa percebeu-se por parte das equipes gestoras dos serviços de saúde no estado um forte apego a territorialização, uma resistência ao modelo organizativo regionalizado e descentralizado, tal realidade que tornou-se comum durante a fase de implantação deste processo em todo Brasil, conforme corrobora Uchimura et al. (2012). Esta confusão em relação ao modelo de estratégia espacial a ser utilizada pela política pública de saúde contribuiu para o adiamento da implantação prática dos termos estabelecidos na NOAS - SUS $01 / 2001$. 
Posteriormente a organização territorial proposta e definida em 2002 precisou ser revista e reformulada em 2006, devido a extensão territorial e os "fluxos sociais, culturais e políticos" (GUIMARÃES, 2012. p.41) que já não condiziam mais com a antiga organização regional da saúde. Assim o mapa da regionalização no estado necessitou ser alterado, criando-se no ano de 2006 a XI GERES. Deste modo, a SES de Pernambuco passou a se organizar territorialmente por meio de onze gerências (figura 2).

Figura 2 - GERES do estado de Pernambuco em 2006

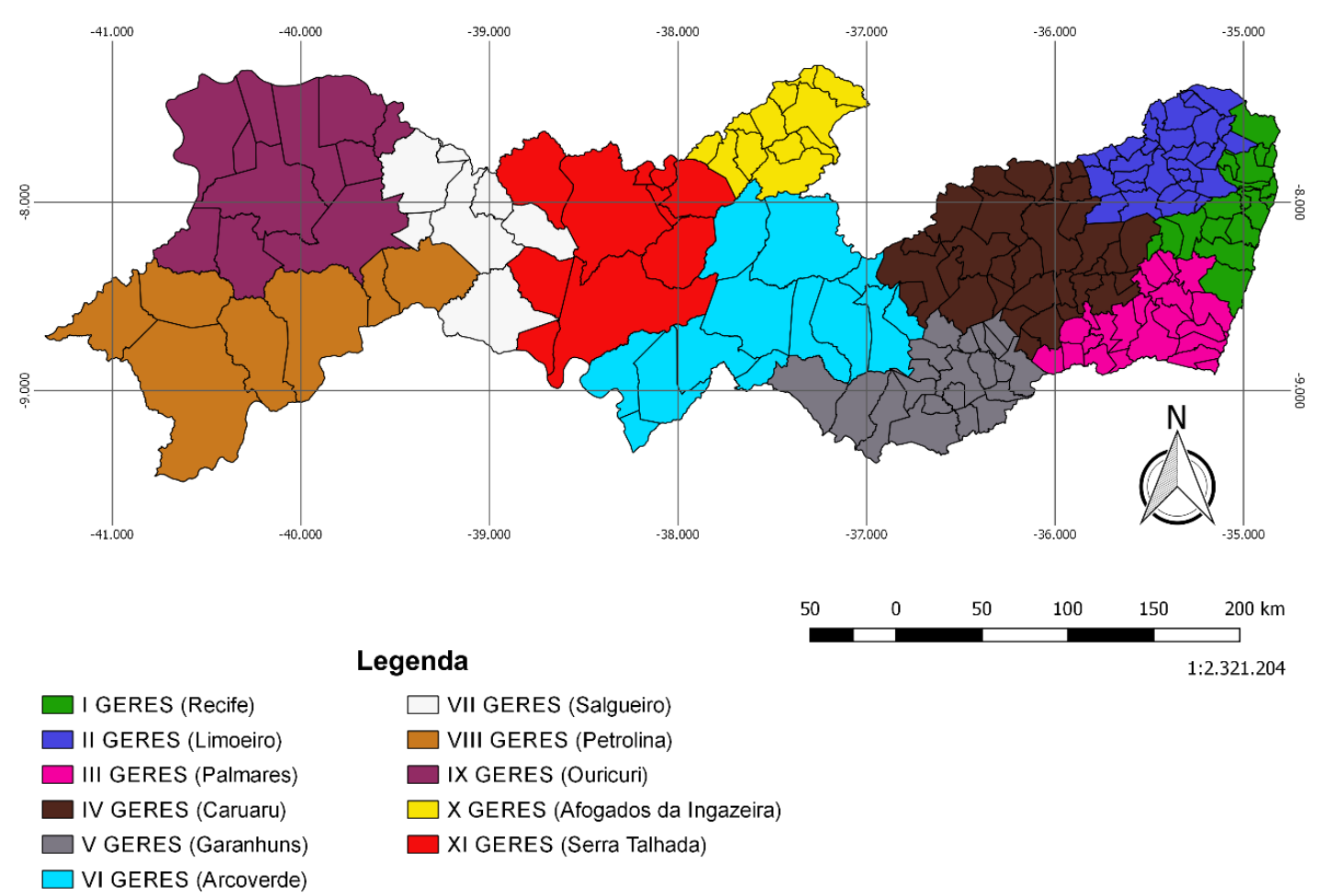

Fonte: PERNAMBUCO, 2009. Adaptado pelo autor.

De acordo com o ilustrado na figura 2, as VI, VII e X GERES foram divididas originando a XI GERES, que possui sede em Serra Talhada e integrou inicialmente a macrorregião de Caruaru, hoje faz parte da terceira macrorregião (Sertão). Considerando os estudos desenvolvidos por Sá (2019) é provável que a escolha da sede regional foi definida com base em alianças políticas e econômicas, uma vez que esta cidade apresenta um histórico de disputa entre famílias que desde sua fundação buscam o controle político, perpetuando sua influência moral e institucional neste município, bem como no estado. De outra forma, devido a extensão territorial das gerências desmembradas e a proximidade de alguns municípios que estavam a margem destas regiões foi necessário a instalação e construção de uma nova rede de atenção à saúde, considerando as ramificações que existiam neste período.

A partir do PES de 2009, que tratava das ações estratégicas para os anos entre 2008 e 2011, o estado de Pernambuco iniciou um processo de adequação da estrutura territorial da saúde às normas e diretrizes estabelecidas no Pacto pela Saúde em 2006. De acordo com Guimarães (2012), a promulgação deste plano iniciou na SES um esforço para a elaboração do novo PDR, como um instrumento ordenador e facilitador do modelo de gestão a ser adotado. Neste novo sistema de organização territorial, estabelecido no âmbito do Ministério da Saúde (MS), conforme estabelece Brasil (2011), se buscava a indivisibilidade territorial, tanto dos municípios quanto dos estados, propondo um movimento dinâmico e flexível através da gestão compartilhada entre os gestores municipais e estaduais. 
Por meio de um estudo que buscou analisar qualitativamente o papel dos gestores na implementação da regionalização dos serviços de saúde no estado de Pernambuco, Guimarães (2012), considera que a descentralização do processo de regulação, controle e avaliação dos serviços de saúde para as GERES e municípios é uma diretriz prioritária. Neste sentido foram estabelecidos pela Portaria $\mathrm{n}^{\circ}$ 817, de 25 de setembro de 2009 da SES de Pernambuco, grupos de trabalho responsáveis por implantar a regionalização no estado, a cargo de um Grupo Tático-Operacional (GTO) e alguns Grupos Temáticos de Trabalho (GTT), responsáveis por operacionalizar a agenda. Estes grupos tinham como prioridade prática elaborar um novo PDR para o estado.

Sob esta lógica organizacional o Estado de Pernambuco definiu que os serviços de atendimento em saúde, são organizados espacialmente pelo PDR de Pernambuco elaborado no ano de 2011 . De acordo com o que determina a lei de implementação do SUS, o estado se divide atualmente em quatro Macrorregiões de Saúde, responsáveis por oferecer aos usuários, os serviços de média e alta complexidade. Os demais serviços e a assistência em saúde são conduzidos pelos princípios da integralidade e equidade, operacionalizada através das GERES, que se articulam entre os municípios e o estado. Na figura 3 observa-se a divisão territorial das macrorregiões estabelecidas pela SES no estado de Pernambuco.

Figura 3 - Macrorregiões de Saúde do Estado de Pernambuco em 2011

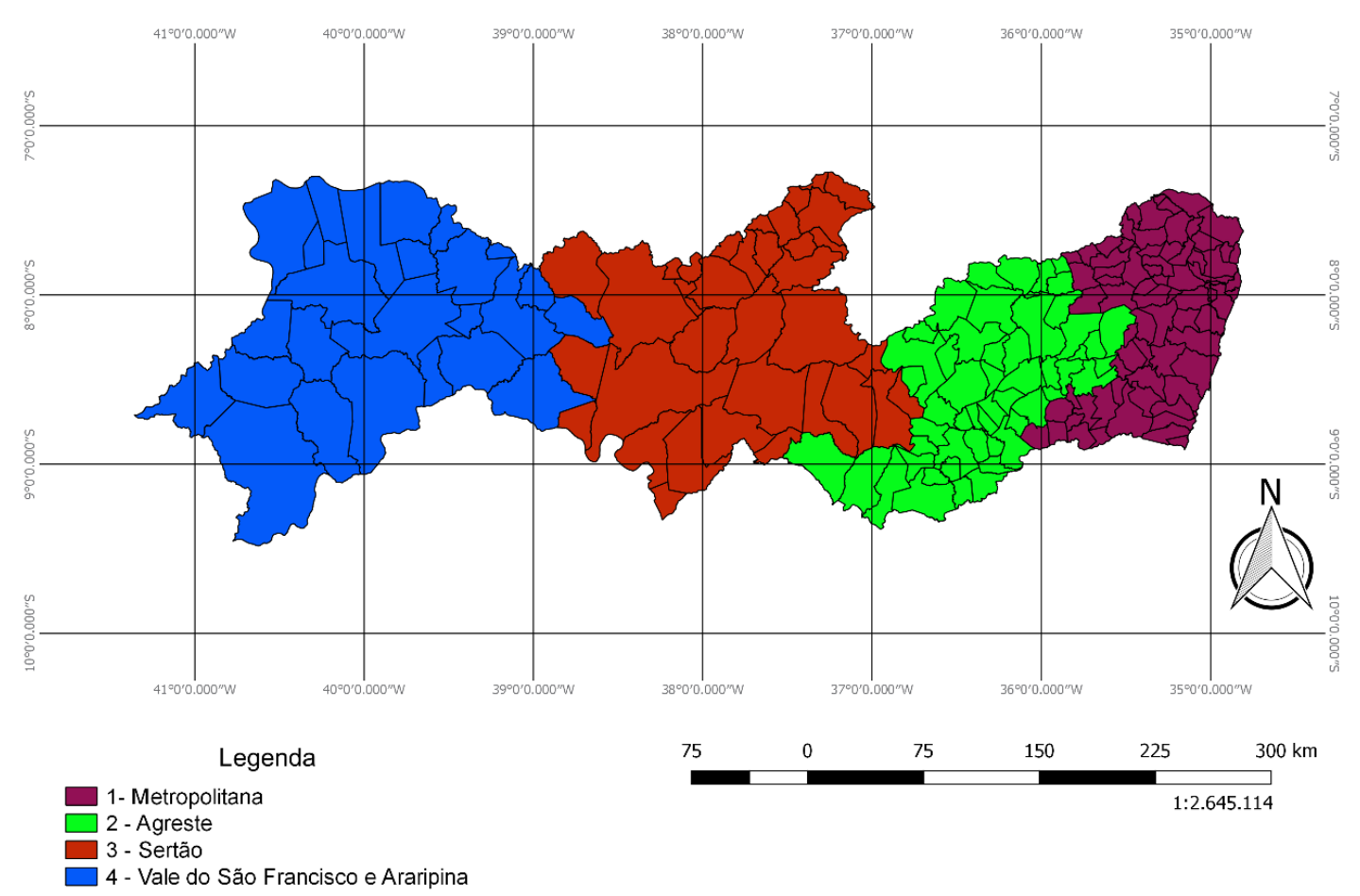

Fonte: Pernambuco, 2011. Adaptado.

A SES de Pernambuco delimitou estrategicamente quatro macrorregiões que do ponto de vista teórico, de acordo com Guimarães (2012), buscam conformar as áreas estrategicamente sob a perspectiva dos territórios sanitários. Nesses espaços organizados regionalmente os serviços de média e alta complexidade devem ser garantidos. Pernambuco (2011) define que em cada macrorregião de saúde do estado deve possuir capacidade para a realização de procedimentos que necessitam de maiores e melhores recursos tecnológicos e que apresentam oferta escassa nos demais limites de conformação da RAS. Isto não significa que na prática todas as macrorregiões disponibilizam aos usuários os serviços de alta complexidade, necessitando-se estudos específicos que avaliem as quatro macrorregiões do estado (Quadro 2). 
Quadro 2 - Distribuição das Macrorregiões de Saúde, suas regiões e Municípios-sede do estado de Pernambuco

\begin{tabular}{|l|c|c|}
\hline \multicolumn{1}{|c|}{$\begin{array}{c}\text { MACRORREGIÕES DE } \\
\text { SAÚDE }\end{array}$} & REGIÃO DE SAÚDE & MUNICíPIOS-SEDE \\
\hline \multirow{4}{*}{ 1.Metropolitana } & I GERES & Recife \\
\cline { 2 - 3 } & II GERES & Limoeiro \\
\cline { 2 - 3 } & III GERES & Palmares \\
\cline { 2 - 3 } & XII GERES & Goiana \\
\hline \multirow{2}{*}{ 2. Agreste } & IV GERES & Caruaru \\
\hline \multirow{3}{*}{ 3. Sertão } & V GERES & Garanhuns \\
\cline { 2 - 3 } & VI GERES & Arcoverde \\
\hline \multirow{2}{*}{$\begin{array}{l}\text { 4. Vale do São Francisco e } \\
\text { Araripe }\end{array}$} & X GERES & Afogados da Ingazeira \\
\cline { 2 - 3 } & XI GERES & Serra Talhada \\
\cline { 2 - 3 } & VII GERES & Salgueiro \\
\cline { 2 - 3 } & VIII GERES & Petrolina \\
\hline
\end{tabular}

Fonte: Pernambuco, 2011. p.12. Adaptado pelo autor.

As macrorregiões se constituem, em conformidade com Pernambuco (2011), como uma organização territorial em que se agregam duas ou mais regiões de saúde, almejando garantir os serviços de maior complexidade à população. Corroborando com a temática, Brasil (2011) afirma que a elaboração das macrorregiões é organizada por meio de redes de atenção que possibilitem a conformação de um sistema integrado de saúde. As macrorregiões auxiliam na hierarquização dos níveis de serviços disponíveis na rede do SUS, definindo-as a partir da possibilidade de prestação de serviços mais complexos.

Por sua vez, as regiões de saúde se estruturam, como definido anteriormente, por meio de espaços que apresentam circunstanciais ligações entre si, objetivando "integrar a organização, o planejamento e a execução de ações e serviços de saúde" (PERNAMBUCO, 2011. p. 6). As GERES são instrumentos fundamentais na elaboração territorial do SUS, por organizarem estrategicamente as ações de saúde em escala local, através das ações de atenção básica e vigilância em Saúde. No estado de Pernambuco atualmente a SES se divide por meio de doze gerências (Figura 4).

O novo formato das regiões de saúde do estado de Pernambuco, foi formulado e definido pelo PDR lançado no ano de 2011. Essas regiões foram delimitadas, de acordo com Pernambuco (2011), por meio da análise dos fluxos assistenciais associados a capacidade instalada em cada município para avaliar o potencial de ampliação de oferta em nível regional, as prospecções do Plano Plurianual (PPA) do Governo Estadual de Pernambuco, que visa identificar possíveis investimentos em regiões potenciais, as identidade culturais e sociais, as atividades econômicas de cada município e a distribuição dos municípios com Índice de Desenvolvimento Humano (IDH) abaixo de 0,70. No entanto, nota-se que as condições geográficas de locomoção e a distância percorrida pelos usuários para acessar os serviços em cada regional não foram consideradas nesta delimitação.

O fator geográfico é preponderante para definir as condições de acesso da população aos serviços prestados. Assis e Jesus (2012) consideram o acesso a partir da possibilidade dos usuários adentrarem aos serviços de saúde. Para eles, a localização da unidade de saúde, a disponibilidade de atendimento, bem como a possibilidade de atendimentos não agendados (Urgência e/ou Emergência) e a percepção que a população tem com relação ao acesso são fatores indispensáveis para mensurar a qualidade do acesso na Atenção Básica em Saúde do Brasil. Além destes elementos, a distância percorrida, as condições de trafego, o tipo de transporte, o valor a ser pago para alcançar os serviços de saúde são variáveis importantes para definir os recortes regionais dos serviços de saúde. 
Figura 4 - GERES do Estado de Pernambuco em 2011

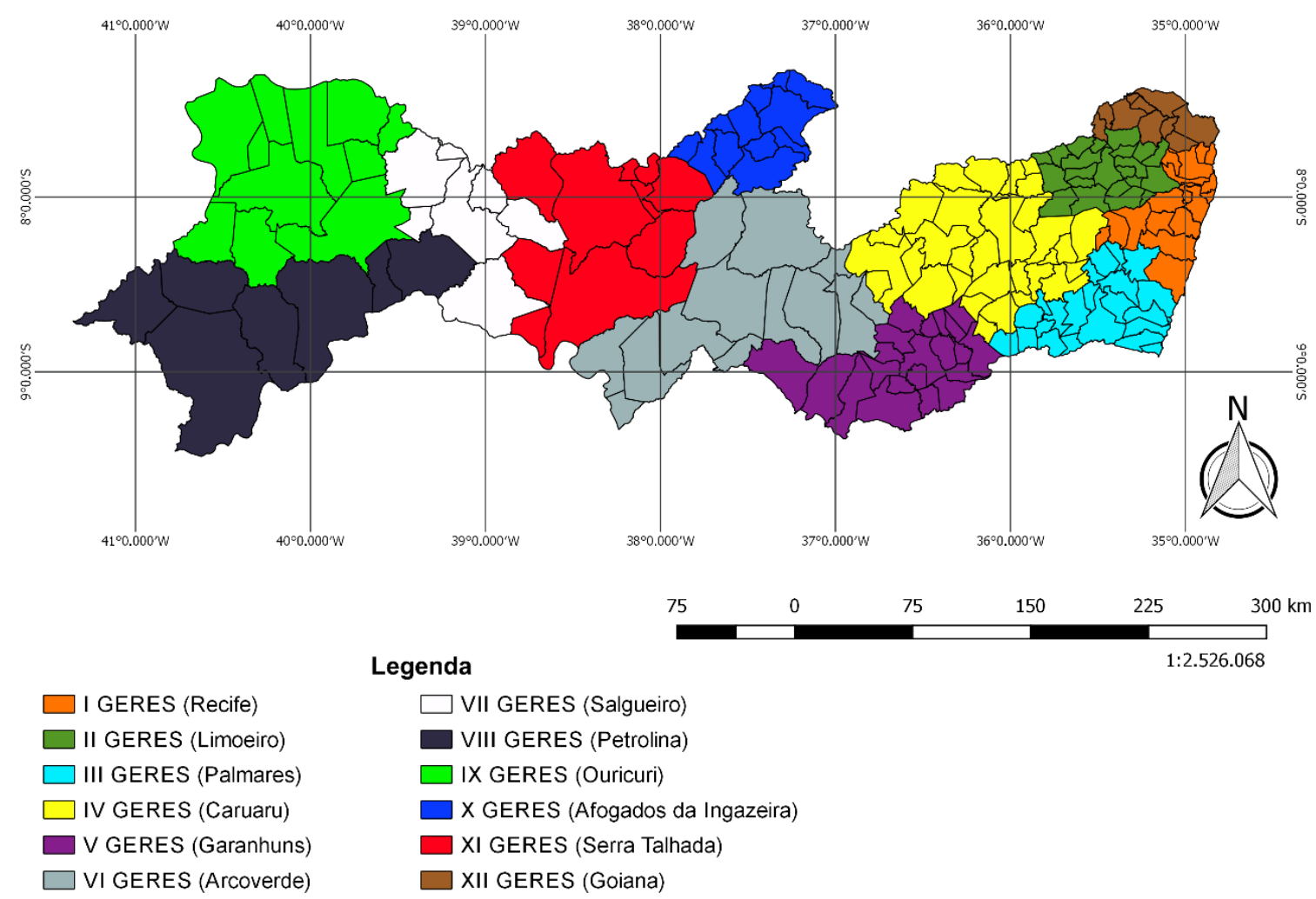

Fonte: PERNAMBUCO, 2011. Adaptado pelo autor.

Com a promulgação do PDR 2011 foi criada a XII GERES da SES de Pernambuco, através do Decreto No 37.772, de 17 de janeiro de 2012. De acordo com Pernambuco (2013), esta região foi implanta com o objetivo de descentralizar e melhorar o serviço de saúde oferecido à população da Mata Norte e do Agreste Setentrional. A nova região de saúde foi estabelecida no território que anteriormente integravam as I e II GERES - PE (Figura 5).

Sendo composta pelos municípios de Aliança, Camutanga, Condado, Ferreiro, Itambé, Itaquitinga, Macaparana, Timbaúba e São Vicente Ferrer, que anteriormente faziam parte da II GERES - PE e o município de Goiana que pertencia a I GERES - PE, como demonstrado na figura 5. A XII GERES PE auxiliou a diminuir territorialmente a II GERES e possibilitou os municípios que localizam-se mais próximos à metrópole estadual integrarem uma nova região. De acordo com Pernambuco (2013) alguns serviços de maior complexidade se configuram ainda no Recife, devido à proximidade com a sede em Goiana e seu potencial de estrutura em saúde.

Como reflexo do novo documento regente da regionalização na saúde do estado ocorreu, de acordo com Pernambuco (2016), a reestruturação das GERES integrantes da SES de Pernambuco. Dentre as ações que visaram reorganizar as gerências de saúde destacam-se a necessidade de concurso público para o cargo de Gerente regional, a criação das coordenações de Atenção à Saúde, de planejamento e regulação e Vigilância em Saúde, bem como a contratação de sanitaristas para cada gerência regional, com a função de auxiliar no planejamento das regiões de saúde. 
Figura 5 - Formação Territorial da XII GERES - PE

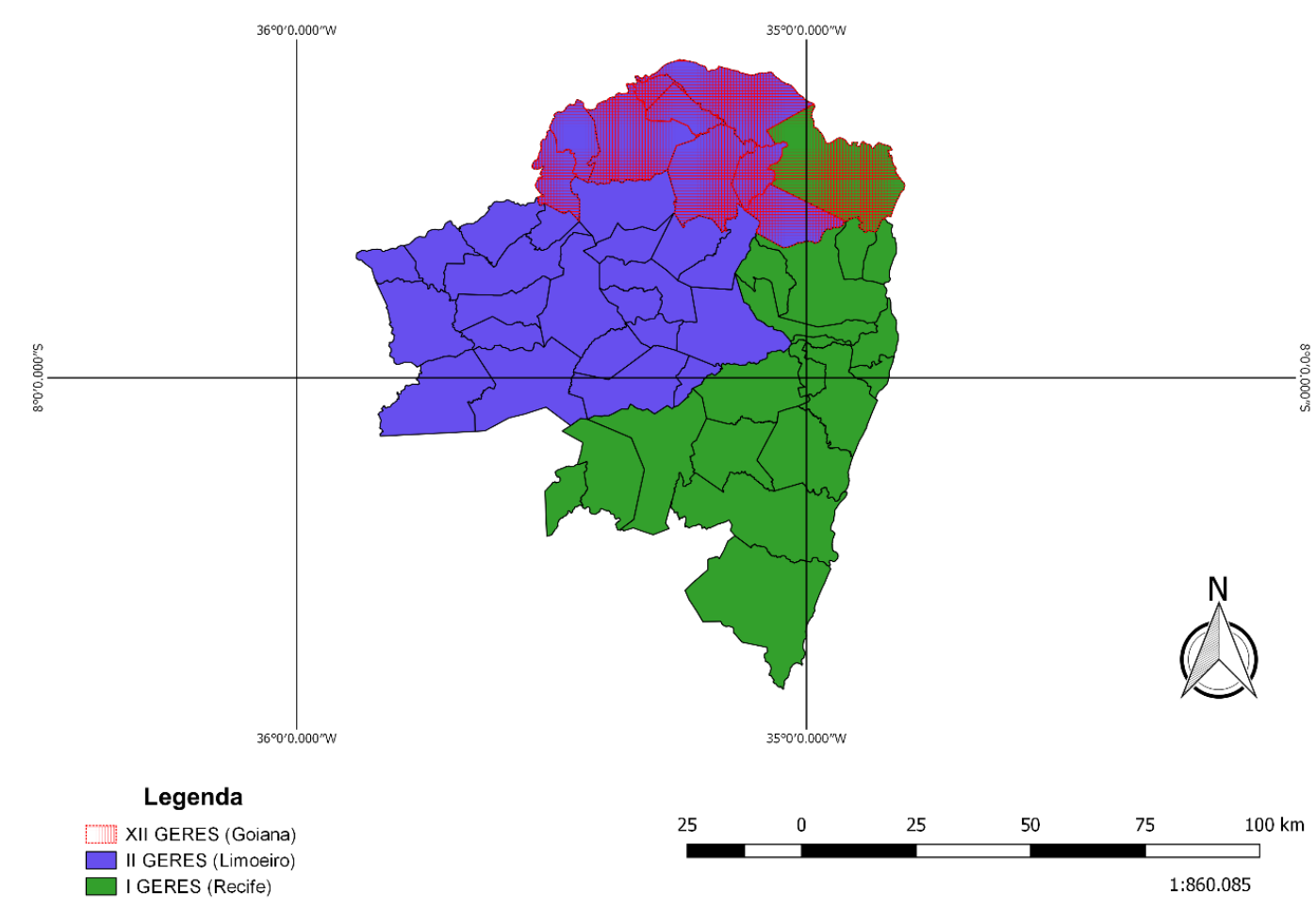

Fonte: Autor, 2018.

Em tese as GERES deveriam possuir um determinado nível de autonomia na execução dos serviços. No entanto, conforme discute Dubeux (2012), persiste uma dependência operativa em relação a Região Metropolitana do Recife (RMR), devido a concentração histórica dos serviços de média e alta complexidade nesta área, tornando a política de regionalização limitada em relação ao seu maior objetivo: a descentralização e garantia de acessibilidade universal e igualitária dos serviços de saúde à toda população. Assim, as regiões de saúde que foram concebidas pelo viés da descentralização ainda apresentam inúmeros entraves que dificultam o sucesso da política de regionalização em saúde no estado.

O atual PES divulgado em 2016 estabelece o uso da "regionalização solidária" (PERNAMBUCO, 2016. p. 152) como um caminho possível para a superação das dificuldades de acesso aos serviços de média e alta complexidade. Destaca ainda que existe um longo caminho a ser percorrido com relação ao cumprimento do papel mais nobre que a regionalização deveria desempenhar, que seria a orientação normativa e organizativa às secretarias municipais de saúde, o que ainda é pouco exercitado. E por fim, indica a revisão e atualização do PDR de 2011, transferindo o município de Cabrobó para a VII GERES - PE, tal alteração justifica-se pelo fator geográfico que foi desconsiderado na formulação definida pelo PDR 2011.

Apesar de todos os avanços e melhoras na organização estrutural do sistema de saúde pernambucano através da efetivação dos princípios de regionalização e descentralização, Dubeux (2012) destaca que qualitativamente a rede básica de atenção à saúde é ainda ineficiente. Para a autora a rede ambulatorial é composta por unidades de saúde, na sua maioria, com baixo poder resolutivo, concentrando o atendimento da média complexidade nas sedes das regionais de saúde e os serviços mais complexos nos municípios de Recife, Caruaru e Petrolina. 


\section{CONSIDERAÇÕES FINAIS}

A trina federativa que inaugurou um caminho de descentralização das políticas públicas do país, a partir da carta constituinte de 1988, delimitou o federalismo sanitário brasileiro. No entanto, tal fator foi ultrapassado por meio da constituição de regiões de saúde que auxiliaram a dinamizar as oportunidades de acesso aos serviços do SUS nos diversos níveis de complexidade, garantindo a universalização e a integralidade dos serviços públicos de saúde no território brasileiro.

O Território se constitui como uma porção específica do espaço terrestre, em que se materializam as relações de poder frente ao uso e ocupação deste espaço. Como meio de organização sócio espacial o território é compreendido como um fragmento em que a organização estrutural define suas finalidades e estratégias de uso e ocupação, determinando as regiões de interesse e exercício de poder. Nesse sentido as políticas públicas apresentam, ou ao menos deveriam apresentar, uma dimensão territorial de sua organização estratégica de atuação e implantação.

A territorialização dos serviços de saúde pode ser considerada como uma estratégia da organização dos serviços de saúde, destacando os recortes geográficos a fim de definir as áreas de atuação das equipes, considerando o número de famílias a serem atendidas, pela Atenção Básica da Saúde, bem como os limites de acesso e disponibilidade aos serviços de média e alta complexidade, por meio das regiões de saúde. Os usuários e profissionais que vivem e conhecem o território devem ser ouvidos e incluídos no processo de organização espacial dos serviços de atenção à saúde, uma vez que esses indivíduos são capazes de identificar e relatar com propriedade os impasses e problemas que devem ser enfrentados para que alcancemos a universalização do serviço de saúde no Brasil.

As políticas de saúde no Brasil passaram por transformações e adaptações que auxiliaram a melhorar as condições de acesso e distribuição dos serviços no território nacional. As redes de atendimento aos serviços de saúde se organizam em um sistema hierárquico, na qual os centros disponíveis com melhores condições de tratamento e cuidado recebem os casos mais graves, oriundos de municípios que não possuem as condições necessárias para o tratamento. Forma-se assim, uma teia de serviços de atenção à saúde, que se relaciona em forma de regiões e redes, almejando garantir a universalização do SUS.

A organização de regiões e redes de atenção à saúde tem sido a estratégia privilegiada nos últimos anos para superar os desafios oriundos da falta de equidade e integração dos serviços prestado. Entre os desafios mais urgentes do SUS estão à ampliação do acesso e a adequação dos serviços ofertados a realidade local de cada espaço geográfico. Nem sempre as dificuldades que as comunidades mais necessitadas enfrentam com relação a saúde são passiveis de similar solução, uma vez que o país apresenta heterogeneidade marcante, fazendo-se necessários mecanismos distintos de integração dinâmica em cada realidade espacial.

A busca pela integração entre os diversos atores responsáveis pelo SUS nos municípios, estados e na federação necessitam atuar de maneira conjunta e participativa visando garantir os princípios fundamentais da Carta Constituinte de 1988. Dessa maneira a política de saúde pública no Brasil poderá alcançar a universalidade e equidade necessárias para que o acesso aos serviços básicos seja garantido de maneira eficiente e resolutiva, atendendo as diretrizes estabelecidas no PDR de cada estado.

\section{REFERÊNCIAS}

ASSIS, M. M. A.; JESUS, W. L. A. Acesso aos serviços de saúde: abordagens, conceitos, políticas e modelo de análise. Ciência \& Saúde Coletiva, v. 17, 2012 . pp. 2865-2875. https://doi.org/10.1590/S1413-81232012001100002

BARCELLOS C.; BASTOS FI. Geoprocessamento, ambiente e saúde, uma união possível? In Cadernos de Saúde Pública, v.12, n.3. Rio de Janeiro, 1996. pp. 389-397. https://doi.org/10.1590/S0102-311X1996000300012

BREVILHERI, E.C.L.; NARCISO, A.M.S.; PASTOR, M. A lógica territorial na política de saúde brasileira. Serviço Social em Revista, v.16, n.2, 2014. pp.36-61. Disponível em: <http://www.uel.br/revistas/uel/index.php/ssrevista/article/view/16348/15184>. https://doi.org/10.5433/1679-4842.2014v16n2p36 
BRASIL. Conselho Nacional de Secretário de Saúde. Sistema Único de Saúde. Brasília: CONASS, 2011.

Constituição da República Federativa do Brasil: texto constitucional promulgado em 5 de outubro de 1988, com as alterações determinadas pelas Emendas Constitucionais de Revisão nos 1 a 6/94, pelas Emendas Constitucionais nos 1/92 a 91/2016 e pelo Decreto Legislativo no 186/2008. - Brasília: Senado Federal, Coordenação de Edições Técnicas, 2016.

DOURADO, D. A.; ELIAS, P. E. M. Regionalização e dinâmica política do federalismo sanitário brasileiro. In Revista de Saúde Pública, v. 45, n. 1. 2011. pp. 204-211. https://doi.org/10.1590/S0034-89102011000100023

DUBEUX, Luciana Santos; CARVALHO, Eduardo Freese de. Caracterização da oferta de serviços especializados em hospitais de referência regional: uma contribuição para a regionalização da assistência à saúde no SUS. Revista Brasileira de Saúde Materno Infantil, v. 9, n. 4, 2009. pp. 467476. https://doi.org/10.1590/S1519-38292009000400012

DUBEUX, L. S. A regionalização da assistência às urgências e emergências em hospitais de referência regional de Pernambuco: uma avaliação sobre a Vertente do Acesso aos Serviços de Saúde. Tese (Doutorado em saúde pública) - Centro de Pesquisas Aggeu Magalhães, Fundação Oswaldo Cruz, 2012.

KADRI, M. R. E. A Regionalização da Saúde: o caminho para o SUS em todos os Territórios? Hygeia: Revista Brasileira de Geografia Médica e da Saúde, v. 15, n. 32, 2019. pp. 6776. https://doi.org/10.14393/Hygeia153351677

FERNANDES, F. M. B. Regionalização no SUS: uma revisão crítica. In Ciência \& Saúde Coletiva, Vol. 22, nº.4, 2017. pp. 1311-1320. https://doi.org/10.1590/1413-81232017224.26412016

GUIMARÃES, R. B. Regiões de saúde e escalas geográficas. In Cadernos de Saúde Pública, Rio de Janeiro, v. 21, n. 4. jul-ago, 2005. pp. 1017-1025. https://doi.org/10.1590/S0102-311X2005000400004

Regionalização da saúde no Brasil: da escala do corpo à escala da nação. Tese (livre-docência) - Universidade de São Paulo, Faculdade de Saúde Pública. São Paulo: [s.n] 2008. $176 \mathrm{p}$.

GUIMARÃES, V. L. B. O processo da regionalização da saúde em Pernambuco, na perspectiva da Gestão Estadual. Dissertação (mestrado) - Universidade Federal de Pernambuco, CCS, Programa de Pós-Graduação em Saúde Coletiva, 2012.

LIMA, L. D.; QUEIROZ, L. F. N.; MACHADO, C. V.; VIANA, A. L. d'A. Descentralização e regionalização: dinâmica e condicionantes da implantação do Pacto pela Saúde no Brasil. In Ciência \& Saúde Coletiva, v. 17, n. 7. [S.I.] 2012. pp. 1903-1914. https://doi.org/10.1590/S1413$\underline{81232012000700030}$

MENDES, E.V. As redes de atenção à saúde. 2 ed. Brasília: Organização Pan-Americana da Saúde, 2011.

PERNAMBUCO. Secretaria Estadual de Saúde. Superintendência de Planejamento. Plano estadual de saúde 2005-2007: desenvolvimento com inclusão social. Recife: SES, 2006.

Secretaria de Saúde. Plano Diretor de Regionalização. [S.I.]. 2011.

Secretaria de Saúde. Mapa Analítico de Saúde da XII Região de Saúde: Pernambuco. Goiana, 2013.

2016.

. Secretaria Estadual de Saúde. Plano estadual de saúde: 2016-2019. Recife: A Secretaria,

PESTANA, M.; MENDES, E. V. Pacto de gestão: da Municipalização Autárquica à Regionalização Cooperativa. Belo Horizonte: Secretaria de Estado de Saúde em Minas Gerais, 2004.

REIS, A. A.C.; SÓTER, A. P. M.; FURTADO, L. A. C.; PEREIRA, S. S. S. Reflexões para a construção de uma regionalização viva. In Ciência \& Saúde Coletiva, v. 22, n. 4. [S.I] 2017. pp. 1045-1054. https://doi.org/10.1590/1413-81232017224.26552016 
SÁ, G. A. D. Compreendendo a construção de um ethos de poder familiar: o caso da oligarquia pereira no interior de Pernambuco. Revista NEP-Núcleo de Estudos Paranaenses da UFPR, v. 5, n. 2, 2019. pp. 46-65. https://doi.org/10.5380/nep.v5i2.70864

UCHIMURA, L. Y. T.; FELISBERTO, E.; FUSARO, E. R.; FERREIRA, M. P.; VIANA, A. L. D. Á. Avaliação de desempenho das regiões de saúde no Brasil. Revista Brasileira de Saúde Materno Infantil, v. 17, 2017. pp. S259-S270. https://doi.org/10.1590/1806-9304201700s100012

VIANA, A. L. d'A; BOUSQUAT, A; MELO, G. A.; NEGRI FILHO, A.; MEDINA, M. G.; Regionalização e Redes de Saúde. In Ciência \& Saúde Coletiva. [S.I.] V. 23, n. 6. 2018. pp. 1791-1798. https://doi.org/10.1590/1413-81232018236.05502018 